\title{
On nonconvex retracts in normed linear spaces
}

\section{GuOWEI ZHANG and PENGCHENG LI}

\author{
ABSTRACT. \\ Let $E$ be a real normed linear space. A subset $X \subset E$ is called a retract of $E$ if there exists a continuous mapping \\ $r: E \rightarrow X$, a retraction, satisfying $r(x)=x, x \in X$. It is well known that every nonempty closed convex \\ subset of $E$ is a retract of $E$. Nonconvex retracts are studied in this paper.
}

Acknowledgements. The authors express their gratitude to the referees for their valuable comments and suggestions. The authors are supported by National Natural Science Foundation of China (Grant number 61473065).

\section{REFERENCES}

[1] Dugundji, J., An extension of Tietze theorem, Pacific J. Math., 1 (1951), 353-367

[2] Dugundji, J., Topology, Allyn and Bacon, INC. Boston, 1978

[3] Granas, A. and Dugundji, J., Fixed Point Theory, Springer, New York, 2003

[4] Guo, D., Cho, Y. J. and Zhu, J., Partial Ordering Methods in Nonlinear Problems, Nova Science Publishers, Inc. New York, 2004

[5] Guo, D. and Lakshmikantham, V., Nonlinear Problems in Abstract Cones, Academic Press, San Diego, 1988

[6] Sun, D. and Zhang, G., Computing the topological degrees via semi-concave functionals, Topol. Methods Nonlinear Anal., 39 (2012), 107-117

[7] Zhang, G. and Li, P., Nonconvex retracts and computation for fixed point index in cones, Topol. Methods Nonlinear Anal., 43 (2014), 365-372

[8] Zhang, G. and Sun J., A generalization of cone expansion and compression fixed point theorem and applications, Nonlinear Anal., 67 (2007), 579-586

Department of MATHEMATics

NORTHEASTERN UNIVERSITY

WENHUA 3-11, 110819 SHENYANG, CHINA

E-mail address: gwzhang@mail.neu.edu.cn, gwzhangneumesina.com

Received: 31.07.2014; In revised form: 02.03.2015; Accepted: 09.03.2015

2010 Mathematics Subject Classification. 54C55, 54C15, 46 T99.

Key words and phrases. Retract, nonconvex, cone.

Corresponding author: Guowei Zhang; gwzhang@mail.neu.edu.cn 